\title{
LAMININ INDUCES ACETYLCHOLINE RECEPTOR AGGREGATION ON CULTURED MYOTUBES AND ENHANCES THE RECEPTOR AGGREGATION ACTIVITY OF A NEURONAL FACTOR ${ }^{1}$
}

\author{
ZVI VOGEL, ${ }^{* 2}$ CLIFFORD N. CHRISTIAN,$\ddagger^{3}$ MARC VIGNY, $\S^{4}$ HANS CHRISTIAN BAUER, $\ddagger^{5}$ \\ PETER SONDEREGGER, $\$$ AND MATHEW P. DANIELS*
}

* Laboratory of Biochemical Genetics, National Heart, Lung and Blood Institute, $\ddagger$ Laboratory of Developmental. Neurobiology, National Institute of Child Health and Human Development, and \& Laboratory of Developmental Biology and Anomalies, National Institute of Dental Research, National Institutes of Health, Bethesda, Maryland 20205

Received August 3, 1982; Revised November 29, 1982; Accepted December 1, 1982

\begin{abstract}
The effect of several basement membrane components on the aggregation of acetylcholine (ACh) receptors on cultured myotubes was studied. Cultures were incubated for 16 to $24 \mathrm{hr}$ with laminin, a heparan sulfate proteoglycan, collagen types IV and V, or fibronectin, alone, or together with medium conditioned by NG108-15 neuroblastoma $\times$ glioma hybrid cells $(\mathrm{NCM})$. The number of ACh receptor aggregates per myotube was assayed by fluorescence microscopy of cultures stained with tetramethylrhodamine-labeled $\alpha$-bungarotoxin.

Laminin induced $\mathrm{ACh}$ receptor aggregation on primary rat myotubes and on myotubes formed by G8-1 clonal rat muscle cells. Laminin enhanced the receptor-aggregating activity of NCM in a concentration-dependent manner $(0.6$ to $6.0 \mu \mathrm{g} / \mathrm{ml})$ and the number of aggregates formed in the presence of laminin and NCM together was greater than the sum of the aggregates induced by NCM and laminin separately. The aggregation factor in NCM is probably not laminin, since less than 10 $\mathrm{ng} / \mathrm{ml}$ of laminin-like immunoreactivity was detected in NCM, and antiserum against laminin blocked the effects of laminin but had little effect on NCM aggregation activity.

Collagen type $\mathrm{V}$ enhanced the receptor aggregation activity of NCM, but less strongly than laminin, and had little or no effect by itself. The other basement membrane components did not induce receptor aggregation or enhance the effect of NCM.

Experiments in which ACh receptors were labeled before exposure of cultures to NCM and laminin indicated that laminin enhanced the rearrangement of receptors at the cell surface. Immunofluorescence microscopy indicated that laminin binds to the myotubes within 30 min and forms patches on the cell surface over a period of hours. Laminin bound to the myotube surface enhanced receptor aggregation as well as laminin continuously present in the culture medium.

The results suggest the possibility that laminin could enhance the receptor aggregation activity of a neuronal factor(s) released at the developing neuromuscular junction.
\end{abstract}

In striated muscle, the role of the basal lamina in the organization of the components of the neuromuscular

\footnotetext{
${ }^{1}$ We are grateful to Mrs. Alice Ling, Lisa Fischetti, and Scott Dubit for technical assistance, and to Marty Green and Irene Smiroldo for secretarial help. The basement membrane proteins and the antiserum against laminin were generously provided by Drs. G. Grotendorst, I. Hassell, H. Kleinman, M. Silver, and G. Martin. The work was supported in part by a grant from the United States-Israel Binational Science Foundation to Z. V., who was the recipient of a Senior Research Fellowship from the Muscular Dystrophy Association and a Research Fellowship from the European Molecular Biology Organization. P. S. was the recipient of a fellowship from the Swiss National Science Foundation.

${ }^{2}$ On sabbatical leave from the Weizmann Institute. Present address:
}

junction has received considerable attention in the past few years. The synaptic basal lamina contains components which induce acetylcholine ( $\mathrm{ACh}$ ) receptor aggregation and other forms of morphological postsynaptic specialization in regenerating muscle fibers (Burden et

Neurobiology Department, The Weizmann Institute of Science, Rehovot P. O. B. 26, Israel.

${ }^{3}$ Present address: Department of Pharmacology, College of Medicine, University of California, Irvine, Irvine CA 92717.

${ }^{4}$ Present address: Laboratoire de Neurobiologie, Ecole Normale Superieure, 46 rue d'Ulm, 95005 Paris, France.

${ }^{5}$ Present address: Inst. fur Molekularbiologie, Abt. Biologie, Billrothstr. 11 A-5020, Salzburg, Austria. 
al., 1979) as well as components which serve as recognition sites for reinnervation and presynaptic specialization (Sanes et al., 1978). Immunohistochemical studies (Sanes and Hall, 1979) have demonstrated the presence of basal lamina components specific to the neuromuscular junction, including acetylcholinesterase (the activity of which has for some time been known to be located at the neuromuscular junction). Ultrastructural studies on the formation of the neuromuscular junction have indicated an early localization of basal lamina at the region of nerve contact (Kelly and Zacks, 1969). Furthermore, myotube regions with a high density of ACh receptors appear to be associated with accumulations of basal lamina both in vivo (Jacob and Lentz, 1979) and in vitro (Burrage and Lentz, 1981). Immunocytochemical studies on cultured clonal muscle cells have demonstrated that two of the same basement membrane components previously shown to be specific to the neuromuscular junction are preferentially (but not exclusively) associated with areas rich in ACh receptors (Silberstein et al., 1982).

In the present study, we have examined the effects of characterized components of the basement membrane on the aggregation of $\mathrm{ACh}$ receptors into high density regions on the surface of rat myotubes grown in cell culture. Since a number of recent studies have shown that extracts of nervous tissue (Podleski et al., 1978; Jessell et al., 1979; Rubin et al., 1980; Kalcheim et al., 1982) as well as medium conditioned by nerve cells in culture (Christian et al., 1978; Jessell et al., 1979; Schaffner and Daniels, 1982) can induce such receptor aggregation, particular attention was paid to the effects of basement membrane components on this aggregation activity. We have found that laminin, a major glycoprotein of the basement membrane (Timpl et al., 1979) induces ACh receptor aggregation and markedly enhances the aggregation induced by conditioned medium from neuroblastoma $\times$ glioma hybrid cell cultures.

\section{Materials and Methods}

Materials. Laminin (Timpl et al., 1979), heparan sulfate proteoglycan (HS proteoglycan (Hassell et al., 1980)), collagen types IV (Orkin et al., 1977) and V (Chung et al., 1976), and fibronectin (Yamada et al., 1976), purified as described in the above references, were generously provided by Drs. G. Grotendorst, J. Hassell, H. Kleinman, M. Silver, and G. Martin of the National Institute of Dental Research, National Institutes of Health, Bethesda, MD. Sheep antiserum against laminin was also provided by Dr. Kleinman. Specificity of the antiserum had been demonstrated by enzyme-linked immunosorbent assay and radioimmunoassay (Foidart et al., 1980) and by immunoadsorption to antigen-coated Sepharose beads (Yaoita et al., 1978). Conditioned medium from cultures of the neuroblastoma $\times$ glioma hybrid cell line NG108-15 (NCM) was prepared as previously described (Bauer et al., 1981), except that the NG108-15 cells were maintained in serum-free N2 culture medium (Bottenstein and Sato, 1979) for 4 days prior to feeding with the medium (Dulbecco's modified Eagle's medium; DMEM) to be conditioned. Either frozen (first concentrated) or lyophilized (first concentrated and dialyzed) NCM preparations were diluted with "control medium" (DMEM with $2 \mathrm{mg} / \mathrm{ml}$ of BSA, $0.75 \mu \mathrm{M}$ tetrodotoxin, and
50 units $/ \mathrm{ml}$ each of penicillin and streptomycin) to the final protein concentrations designated under "Results." Protein concentration was determined according to the method of Lowry et al. (1951).

Cell cultures. Cultures of dissociated muscle cells from the hindlimbs of 19- to 21-day-old fetal Sprague-Dawley rats were prepared as described previously (Schaffner and Daniels, 1982), by plating 3 to $5 \times 10^{5}$ cells $/ 35-\mathrm{mm}$ tissue culture dish in $80 \%$ DMEM, $10 \%$ fetal calf serum, $10 \%$ heat-inactivated horse serum. After 4 to 5 days the cultures were fed with $90 \%$ DMEM, $10 \%$ horse serum, 5.4 $\mu \mathrm{M}$ fluorodeoxyuridine, and $13.2 \mu \mathrm{M}$ uridine to reduce the background of nonmuscle cells. After one additional day, the cultures were fed with $90 \%$ DMEM, $10 \%$ horse serum containing $0.75 \mu \mathrm{M}$ tetrodotoxin to prevent myotube contraction and were fed with the same medium every 3 days thereafter. Cells of the G8-1 muscle line (Christian et al., 1977; Peacock et al., 1977; Sugiyama, 1979) were grown in 90\% DMEM, $10 \%$ fetal calf serum. Cells were removed from the culture flasks by 5 min treatment at room temperature with $0.1 \%$ crystalline trypsin in Dulbecco's phosphate-buffered saline (DPBS; Dulbecco and Vogt, 1954) without $\mathrm{Ca}^{++}$and $\mathrm{Mg}^{++}$. The trypsinized cells were mixed with several volumes of $90 \%$ DMEM, $10 \%$ heat-inactivated horse serum, pelleted and resuspended in DMEM containing $1 \%$ heat-inactivated horse serum, and plated at a density of $5 \times 10^{5}$ cells $/ 35-\mathrm{mm}$ collagen-coated plastic tissue culture dish, in $1.5 \mathrm{ml}$ of the same medium. Under these conditions, the cells fused into multinucleated myotubes in a few days. 'The cultures were fed again on the 4th day and used on the 8th day after plating.

Experimental treatment of cultures. Prior to experiments, cultures were treated with "control medium" as described previously (Bauer et al., 1981). The amount of NCM added to cultures is expressed as micrograms of protein per milliliter. Except where otherwise noted, incubation of the cultures with NCM and/or basement membrane components was for 16 to $24 \mathrm{hr}$ in a total volume of $1.0 \mathrm{ml}$ and was terminated by replacing the culture medium with medium containing $100 \mathrm{nM}$ tetramethylrhodamine-conjugated $\alpha$-bungarotoxin (TMR$\alpha \mathrm{BT}$ ) and incubating $1 \mathrm{hr}$ at $37^{\circ} \mathrm{C}$, to label ACh receptors, followed by determination of the average number of receptor aggregates per myotube segment as described previously (Schaffner and Daniels, 1982). The term, relative number of ACh receptor aggregates, used in this article ("Results") is the mean number of aggregates per myotube segment (from at least 20 fields of $0.24 \mathrm{~mm}^{2}$ in each of duplicate cultures, except where otherwise noted) under a given experimental condition, divided by the mean number of aggregates per myotube segment in control cultures. All quantitative experiments were performed at least twice, with reproducible results.

Immunofluorescence staining for laminin. Muscle cell cultures were fixed with $2 \%$ paraformaldehyde, $0.1 \mathrm{M}$ sodium phosphate buffer, $\mathrm{pH} 7.2$, and were washed for 2 $\mathrm{hr}$ with several changes of DPBS and for $10 \mathrm{~min}$ with 90\% DPBS, 10\% normal rabbit serum (DPBS-serum). The cultures were then incubated for $1 \mathrm{hr}$ with laminin antiserum diluted 1:2000 with DPBS-serum, washed sevcral times with DPBS-serum, incubated for $1 \mathrm{hr}$ with fluorescein isothiocyanate-conjugated $F\left(a b^{\prime}\right)_{2}$ fragment 
of IgG from rabbit anti-goat IgG $(20 \mu \mathrm{g} / \mathrm{ml}$; N. L. Cappel Laboratories, West Chester, PA) washed again, and mounted in buffered glycerol, $\mathrm{pH}$ 8.0. Cultures were examined with a Zeiss Photomicroscope II equipped with a 50-W mercury arc lamp and epifluorescence optics, a $\times 25$ plan neofluor phase contrast immersion objective (N.A. 0.8), a BP $485 / 20$ excitation filter, and an LP 520 barrier filter. Fluorescence photomicrographs were taken at 30 -sec exposures on Ilford HP-5 film processed to ASA 800 .

\section{Results}

$A C h$ receptor distribution and the effects of NCM and laminin. As previously shown (Vogel et al., 1972; Fischbach and Cohen, 1973; Sytkowski et al., 1973; Axelrod et al., 1976), the surfaces of cultured rat myotubes have both diffusely distributed ACh receptors and regions with a high receptor density, which we refer to as "receptor aggregates" (Fig. 1). Two types of receptor aggregates are easily distinguished by fluorescence microscopy of cultures labeled with TMR- $\alpha$ BT. Most of the receptor aggregates found in the cultures were broad patches (200 to $500 \mu \mathrm{m}^{2}$ ) on the ventral side of the myotubes at regions of cell-substratum adhesion (Bloch and Geiger, 1980) and are referred to here as "ventral patches." Receptor aggregates are also found on the edges and dorsal surfaces of the rat myotubes (Christian et al., 1978). Since these are generally long and narrow in appearance, they are referred to as "linear aggregates." Under conditions promoting extensive receptor aggregation, some aggregates of "linear" shape form on the ventral surface of the myotubes. These too were classified as "linear aggregates."

When cultures were treated with NCM, there was an increase in the number of linear aggregates (Fig. $1 C$; see Christian et al., 1978). A more striking increase in the number of linear aggregates occurred when the cultures were incubated with NCM in the presence of laminin (Fig. 1D). The number of ventral patches did not seem to increase in the presence of NCM or NCM plus laminin and, in fact, appeared to decrease in some experiments with laminin or NCM plus laminin. Despite this loss of ventral patches, a striking overall increase in aggregated receptors was apparent on examination of cultures treated with NCM plus laminin.

These qualitative observations were confirmed in quantitative assays of the number of receptor aggregates per myotube (Fig. 2). The total number and the number of linear aggregates were increased by 150 and $360 \%$, respectively, in the presence of NCM alone. (The relatively higher effect for linear than total aggregates reflects the observation mentioned above that only linear aggregates increase in the presence of NCM and that their number in control cultures is relatively small.) The addition of laminin enhanced this effect in a concentration-dependent manner, with an approximate saturation at $3 \mu \mathrm{g} / \mathrm{ml}$ of laminin. The relative increase in the number of receptor aggregates obtained with NCM plus $3 \mu \mathrm{g} / \mathrm{ml}$ of laminin was $350 \%$ for total aggregates and $950 \%$ for linear aggregates, compared to the controls. Laminin alone caused a smaller increase in the total number of receptor aggregates and linear aggregates. The increase in aggregation caused by NCM and laminin added at the same time was more than the sum of the increases caused by NCM and laminin separately. Moreover, even concentrations of laminin or NCM several times above the levels used here did not increase aggregation separately to the extent shown here for laminin and NCM together (data not shown). The number of ventral receptor patches was not significantly changed by NCM treatment alone, but was decreased by 20 to $70 \%$ in the presence of laminin alone or with NCM and laminin together.

Experiments with G8-1 clonal muscle cell cultures gave results similar to those obtained with primary cultures. As seen in Figure 3B, G8-1 myotubes have few receptor aggregates. The number of aggregates increased moderately in the presence of NCM and several-fold more with laminin and NCM (Fig. 3, $C$ and $D$ ). The receptor aggregates on G8-1 myotubes were small $\left(10\right.$ to $\left.100 \mu \mathrm{m}^{2}\right)$ and were usually elongate. Different morphological types of receptor aggregates were not distinguished for quantitative purposes in G8-1 cultures. As shown quantitatively in Figure 4, the enhancement of the aggregation activity of NCM by laminin was concentration dependent with an approximate saturation at 3 to $4 \mu \mathrm{g} / \mathrm{ml}$. As with primary cultures, the effect of laminin alone was relatively small. 'The relative increase in the number of receptor aggregates obtained with NCM plus $3.6 \mu \mathrm{g} / \mathrm{ml}$ of laminin was $600 \%$, while NCM alone caused an increase of $170 \%$ and laminin alone caused an increase of $110 \%$. Thus, as with primary cultures, the effect of laminin and NCM together on G8-1 clonal muscle cells was greater than the sum of their individual effects.

The relationship of laminin to the receptor-aggregating activity in NCM. Because laminin has demonstrated receptor-aggregating activity and there is evidence that neuroblastoma cell lines secrete laminin or laminin subunits (Alitalo et al., 1980), we investigated the possibility that the aggregating activity in NCM could be accounted for by the presence of laminin. The following results suggest that this is not the case. First, using an enzymelinked immunosorbent assay for soluble laminin as described previously (Rennard et al., 1980), with a sensilivity to $10 \mathrm{ng} / \mathrm{ml}$, no laminin was detected in the $\mathrm{NCM}$ used in this study. Second, the addition of specific antiserum against laminin to the culture medium at a concentration (1:300 dilution) sufficient to eliminate the effects of laminin had only a small effect on the aggregation activity of NCM. At the same concentration, the antiserum reduced the number of aggregates obtained in the presence of NCM plus laminin to a level close to that obtained with NCM alone (Fig. 5).

Effects of other basement membrane components. The ability of other purified basement membrane components to cause $\mathrm{ACh}$ receptor aggregation or to enhance the aggregation caused by NCM was tested. Fibronectin, collagen type IV, and HS proteoglycan had little or no effect on receptor aggregation in the presence or absence of NCM at concentrations up to 25,33 , or $50 \mu \mathrm{g} / \mathrm{ml}$, respectively. Collagen type V, at 4 to $20 \mu \mathrm{g} / \mathrm{ml}$, had a relatively small effect (if any) on receptor aggregation by itself, but $4 \mu \mathrm{g} / \mathrm{ml}$ of collagen type $\mathrm{V}$ enhanced the effect of NCM by increments of 160,230 , and $290 \%$ relative to controls in three experiments, a weaker effect than that 

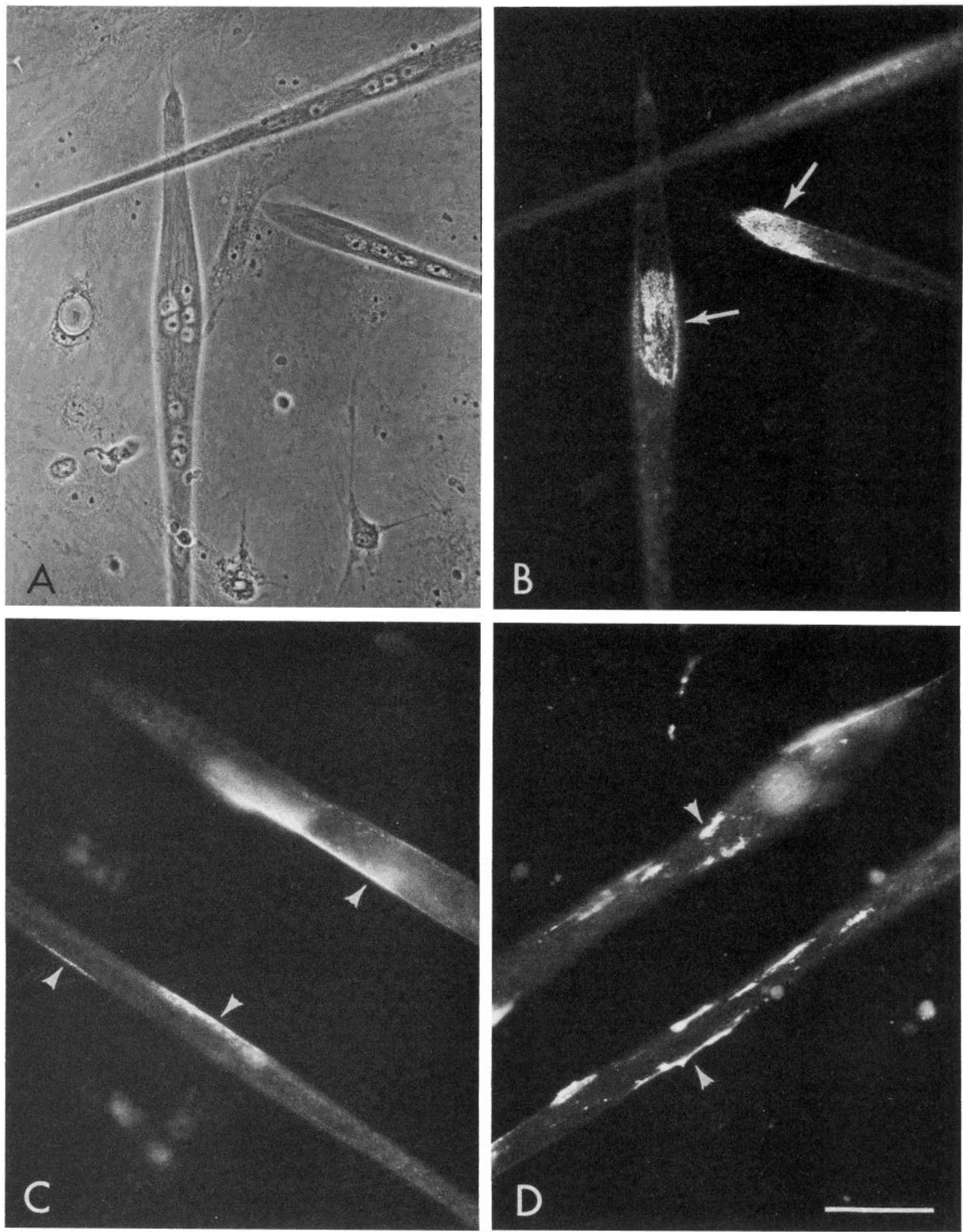

Figure 1. Phase contrast $(A)$ and fluorescence $(B$ to $D)$ photomicrographs of myotubes in 10-day-old rat muscle cell cultures which were labeled with TMR- $\alpha \mathrm{BT}$ after incubation with control medium $(A$ and $B), 40 \mu \mathrm{g}$ of NCM $(C)$, or $40 \mu \mathrm{g}$ of NCM and $4.2 \mu \mathrm{g}$ of laminin $(D)$. Broad ventral patches of ACh receptor, which are predominant in the control cultures, are indicated by arrows in $B$ (some ventral patches, out of the plane of focus, are seen in $C$ and $D$ ). Examples of linear ACh receptor aggregates, which form after incubation with NCM and NCM plus laminin, are indicated by arrowheads $(C$ and $D)$. The calibration bar is $50 \mu \mathrm{m}$. 

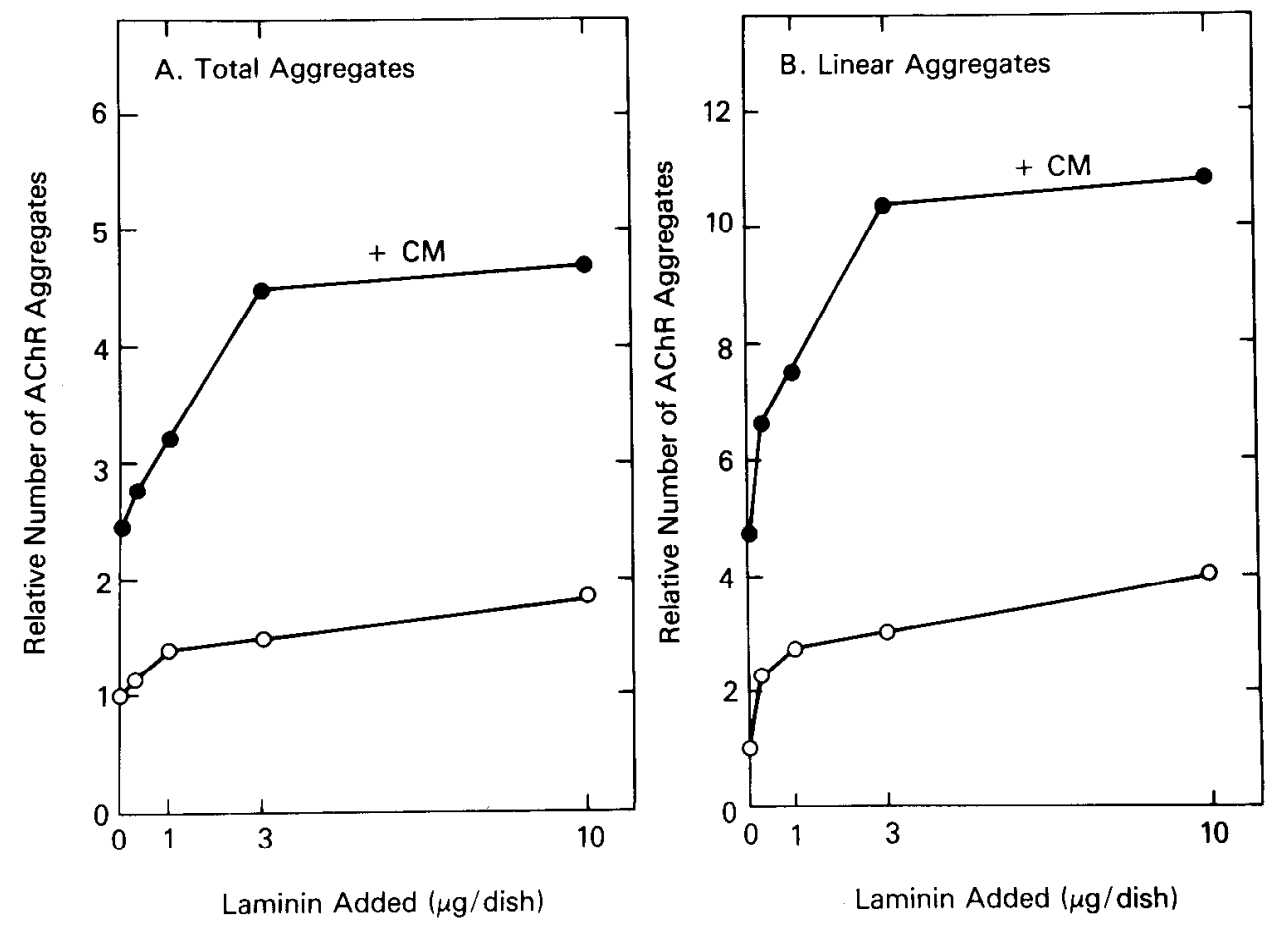

Figure 2. The effect of NCM and laminin on the total number of ACh receptor $(A C h R)$ aggregates $(A)$ and linear aggregates $(B)$ in rat muscle cell cultures. Myotubes in 10-day-old cultures were incubated with the specified amounts of laminin in the presence (- - ) or absence (-O-) of $40 \mu \mathrm{g}$ of NCM $(C M)$. The total number of receptor aggregates per myotube segment and the number of linear aggregates were determined in single cultures (duplicate cultures were used in all other experiments shown) after staining with TMR- $\alpha \mathrm{BT}$. The ordinate shows the relative number of total $(A)$ or linear $(B)$ receptor aggregates per myotube segment, with the relative number (total or linear) of receptor aggregates in control cultures defined as 1 . The ordinate is the same in all graphs that follow.

of laminin. Increasing the concentration of collagen type $\mathrm{V}$ to $20 \mu \mathrm{g} / \mathrm{ml}$ caused only a small increase enhancement of the NCM effect.

Mechanism of the laminin effect. Because laminin caused a marked enhancement of $\mathrm{ACh}$ receptor aggregation by NCM, experiments were performed in order to investigate the mechanism of this effect. It had been shown previously that NCM could induce receptor aggregation under conditions where protein synthesis was blocked, and that receptors present on the myotube surface before the addition of NCM were rearranged into receptor aggregates (Christian et al., 1978). In the present study (Fig. 6), when ACh receptors were labeled with TMR- $\alpha \mathrm{BT}$ before the addition of NCM or laminin, both NCM and laminin caused significant aggregation, although somewhat less than in postlabeled cultures. Furthermore, the ability of laminin to enhance the aggregating activity of NCM was not reduced significantly by prelabeling the receptors (i.e., the ratio of the effect of NCM plus laminin to the effect of NCM alone was similar in prelabeled and postlabeled cultures.) Thus, the enhancement of $\mathrm{ACh}$ receptor aggregation by laminin seems to be largely an enhancement of receptor rearrangement at the cell surface.

The effects of laminin on receptor aggregation were eliminated by heating the laminin to $100^{\circ} \mathrm{C}$ for $10 \mathrm{~min}$ in a boiling water bath (data not shown). This suggests that this glycoprotein had to be in its native configuration in order to induce or enhance receptor aggregation.
The interactions between the myotubes, NCM, and laminin with regard to receptor aggregation were further investigated by adding either laminin or NCM to cultures for only $2 \mathrm{hr}$, washing the cultures, and then incubating with the complementary component (either NCM or laminin) for an additional $22 \mathrm{hr}$. For comparison, other cultures were treated with either laminin or NCM for 2 hr before washing and $22 \mathrm{hr}$ incubation with control medium, or were treated for $24 \mathrm{hr}$ with laminin and NCM together (Fig. 7). The results show that treatment with NCM or laminin for $2 \mathrm{hr}$ followed by washing was much less effective than continuous treatment for $24 \mathrm{hr}$, but when cultures were treated for $2 \mathrm{hr}$ with laminin, washed, and then treated for $22 \mathrm{hr}$ with NCM, aggregation activity was equivalent to that obtained with continuous treatment with laminin and NCM. The effect of NCM preincubation followed by laminin was intermediate between that of laminin alone and that of NCM plus laminin for $24 \mathrm{hr}$. These results suggest that both laminin and NCM can interact with the myotubes within $2 \mathrm{hr}$ so as to stimulate further receptor aggregation, providing that the complementary component is added. Moreover, the potent effect of preincubation with laminin followed by NCM addition suggests that laminin may enhance the aggregation activity of NCM through a relatively stable binding of laminin to the myotubes.

Direct evidence for such binding was obtained by adding $6 \mu \mathrm{g} / \mathrm{ml}$ of laminin to myotube cultures for various lengths of time, washing, and fixing the cultures, and 

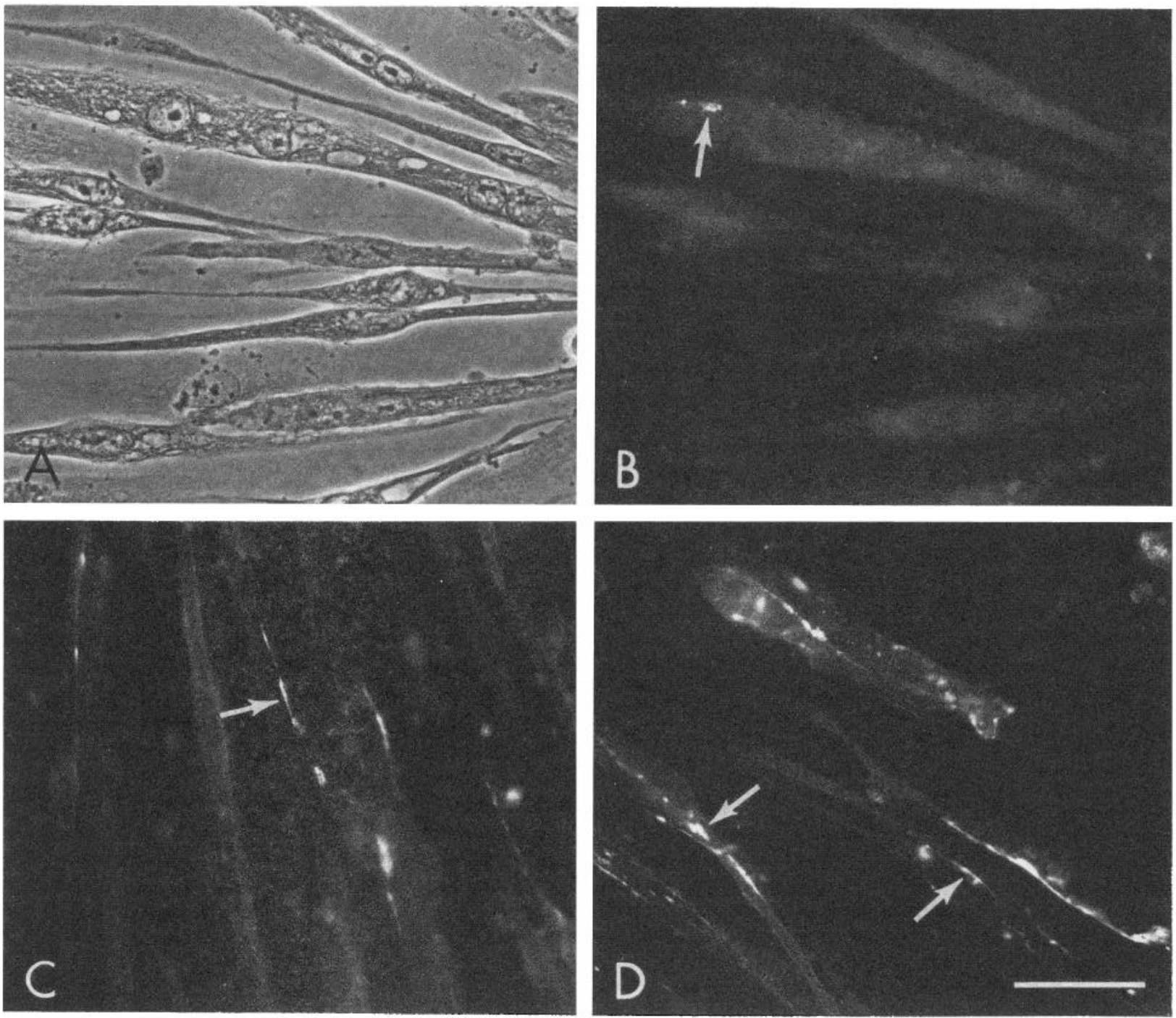

Figure 3. Phase contrast $(A)$ and fluorescence $(B$ to $D)$ photomicrographs of myotubes in 7-day-old G8-1 muscle cell cultures which were labeled with TMR- $\alpha \mathrm{BT}$ after incubation with control medium ( $A$ and $B), 0.8 \mathrm{ml}$ of NCM (not concentrated), prepared as described previously (Bauer et al., 1981) and $0.2 \mathrm{ml}$ of control medium $(C)$, and NCM plus $3.6 \mu \mathrm{g}$ of laminin $(D)$. The ACh receptor aggregates (examples indicated by arrows) are generally smaller than those seen in primary cultures (Fig. 1). The calibration bar is $50 \mu \mathrm{m}$.

then visualizing the surface-bound laminin by indirect immunofluorescence. Myotubes in cultures grown under the conditions described here had relatively little laminin on their surfaces, except for a few concentrated patches (Fig. 8, $A$ and $B$; Daniels et al., 1981; M. P. Daniels, M. Vigny, P. Sonderegger, H. -C. Bauer, and Z. Vogel, submitted for publication). The results clearly showed binding of added laminin to the muscle cell surface (as well as to nonmuscle cells) as early as $30 \mathrm{~min}$, the shortest time point taken (Fig. 8, $D$ and $E$ ). Little or no laminin binding was detected on the culture substratum. Total binding of laminin did not seem to increase after $2 \mathrm{hr}$ (not shown); however, the distribution of laminin on the cell surface gradually changed from a relatively even, finely granular pattern to a distinctly aggregated pattern between $30 \mathrm{~min}$ and $24 \mathrm{hr}$ (Fig. 8, D, E, and $G$ ).

\section{Discussion}

Myotubes grown in cell culture from dissociated embryonic muscle tissue (Vogel et al., 1972; Fischbach and
Cohen, 1973; Sytkowski et al., 1973) and from cells of clonal muscle lines (Sytkowski and Vogel, 1973; Podleski et al., 1978; Silberstein et al., 1982) have the capacity to form receptor aggregates in their plasma membranes, in the absence of innervation. In the past few years, several laboratories have reported that neuronal cells and tissues produce macromolecular factors which can increase the number of receptor aggregates on cultured myotubes (Christian et al., 1978; Podleski et al., 1978; Jessell et al., 1979; Rubin et al., 1980; Schaffner and Daniels, 1982). In the present study, we have shown that laminin, a basement membrane glycoprotein (Timpl et al., 1979), can induce receptor aggregation on cultured rat myotubes in primary cultures and cultures of the G8-1 cell line. Moreover, we have shown that laminin can enhance the receptor aggregation activity of NCM (Christian et al., 1978). It is interesting to note that the receptor aggregates formed in the presence of NCM, laminin, or NCM and laminin together were of the "linear" type referred to under "Results," whereas there was no increase in the 


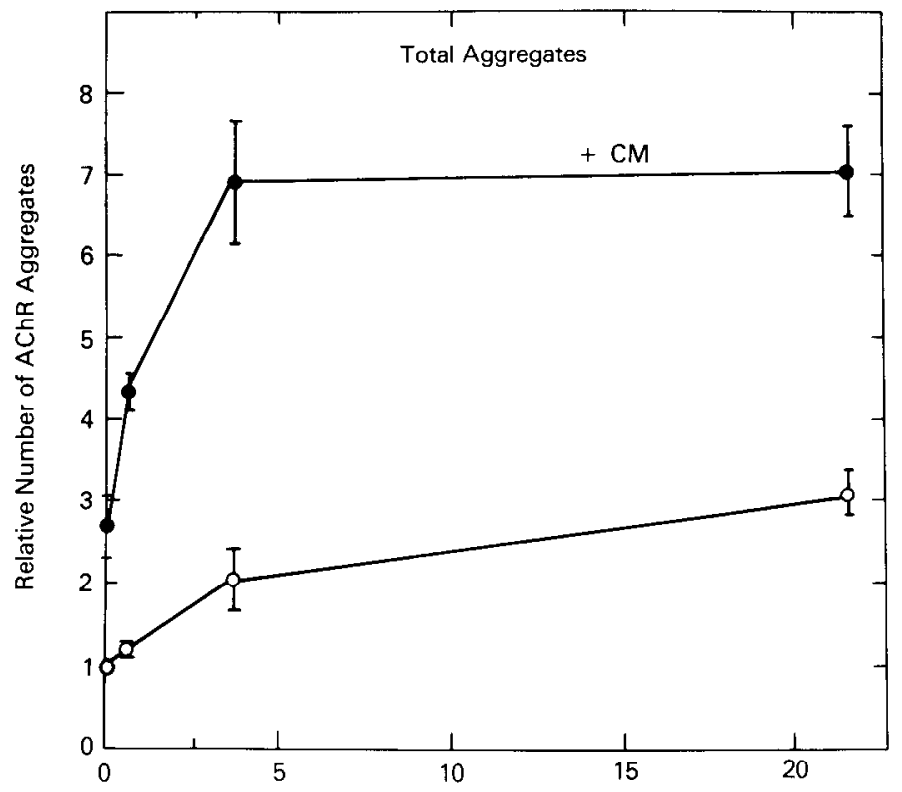

Laminin Added $(\mu \mathrm{g} /$ dish)

Figure 4. The effect of NCM and laminin on the total number of ACh receptor $(A C h R)$ aggregates in 7-day-old G8-1 muscle cell cultures. Treatment with NCM was as described in the legend to Figure 3. - - , treatment with NCM $(C M)$; treatment without NCM.

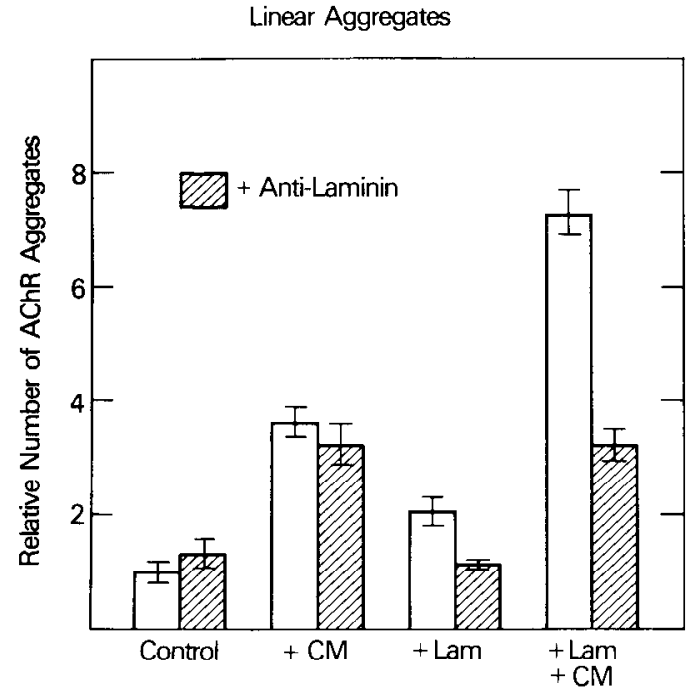

Figure 5. The effect of antiserum against laminin on the number of linear $\mathrm{ACh}$ receptor $(A C h R)$ aggregates in rat muscle cell cultures incubated with control medium (Control), laminin ( Iam), NCM $(C M)$, or laminin phus NCM. Ten-day-old cultures were incubated in the presence (hatched bars) or absence (open bars) of $3 \mu \mathrm{l}$ of antiserum against laminin. NCM $(60 \mu \mathrm{g})$ was added to the cultures as indicated, followed immediately by the addition of antilaminin, as indicated, and 30 min later by the addition of laminin $(6 \mu \mathrm{g})$ as indicated. Addition of antilaminin to the diluted NCM $15 \mathrm{~min}$ before adding the NCM to the cultures gave results similar to those shown here (data not shown).

number of "ventral patches" found at regions of adhesion (Bloch and Geiger, 1980) on the lower surface of the myotubes. In fact, when receptor aggregation was strongly enhanced by NCM together with laminin, a marked decrease in the number of ventral patches per myotube segment was detected. Ventral patches seem to consist of clusters of mary very small aggregates (Axelrod et al., 1976) and it is interesting to speculate on the possibility that these very small aggregates could be rearranged to form the intensely fluorescent linear aggregates. In agreement with our observations, a recent report (Salpeter et al., 1982) has indicated that treatment with brain extract can cause a redistribution of high $\mathrm{ACh}$ receptor density sites from the bottom of the cell to the top, in conjunction with an increase in pcak reccptor site density.

The observation of receptor aggregation activity in a high molecular weight glycoprotein such as laminin suggested that the activity in neuronal conditioned medium was due at least in part to laminin itself or a closely related molecule. This possibility is supported by the finding (Alitalo et al., 1980) that some cultured neuroblastoma cells release basement membrane proteins, including some with the molecular weight and immunoreactivity of the two laminin subunits. Although we cannot rule out this possibility at present, some of our findings do not support the idea. First, less than $10 \mathrm{ng} /$ $\mathrm{ml}$ of laminin was detected in NCM by enzyme-linked immunosorbent assay, while 1 to $10 \mu \mathrm{g} / \mathrm{ml}$ of laminin was required to induce receptor aggregation. Second, although antiserum against laminin virtually eliminated the effects of laminin on aggregation, it had relatively little effect on the activity of NCM. Third, the effects of laminin and NCM together were more than additive and the aggregation obtained with saturating concentrations of laminin could be further enhanced by addition of NCM. An additional point is that the apparent $M_{\mathrm{r}}$ of the NCM aggregation factor is 150,000 to 250,000 (Bauer et al., 1981), whereas the $M_{\mathrm{r}}$ of laminin is close to 800,000 . However, it is not known whether the $M_{\mathrm{r}}=200,000$ subunit of laminin has aggregation activity.

Among the basement membrane components tested in this study, collagen type $\mathrm{V}$ was the only one besides laminin to reproducibly show enhancement of NCMinduced aggregation. This activity was considerably less than that observed with laminin. Stimulation of aggregation activity by collagen would be consistent with the finding that various conditions which effect collagen accumulation also affect $\mathrm{ACh}$ receptor aggregation (Kalcheim et al., 1982).

The mechanism by which laminin and NCM induce the formation of $\mathrm{ACh}$ receptor aggregates is not yet clear. The aggregating activity cannot be accounted for simply by an increase in the number or stability of receptor molecules, since NCM and laminin together produced an increase of less than $20 \%$ in receptor number (Z. Vogel, unpublished observation; see also Christian et al., 1978) and laminin had a negligible effect on receptor half-life, either alone or above the effect of NCM alone (Z. Vogel, unpublished observation; see also Hasegawa et al., 1980; Christian et al., 1981). A second possibility, not yet tested, is that $\mathrm{ACh}$ receptor aggregates which are formed in the presence of NCM and might otherwise disappear over a period of hours are stabilized by laminin. The results reported here may also be explained by some form of cooperative interaction between laminin and the factor(s) in NCM. Laminin can bind to the myotubes within 30 


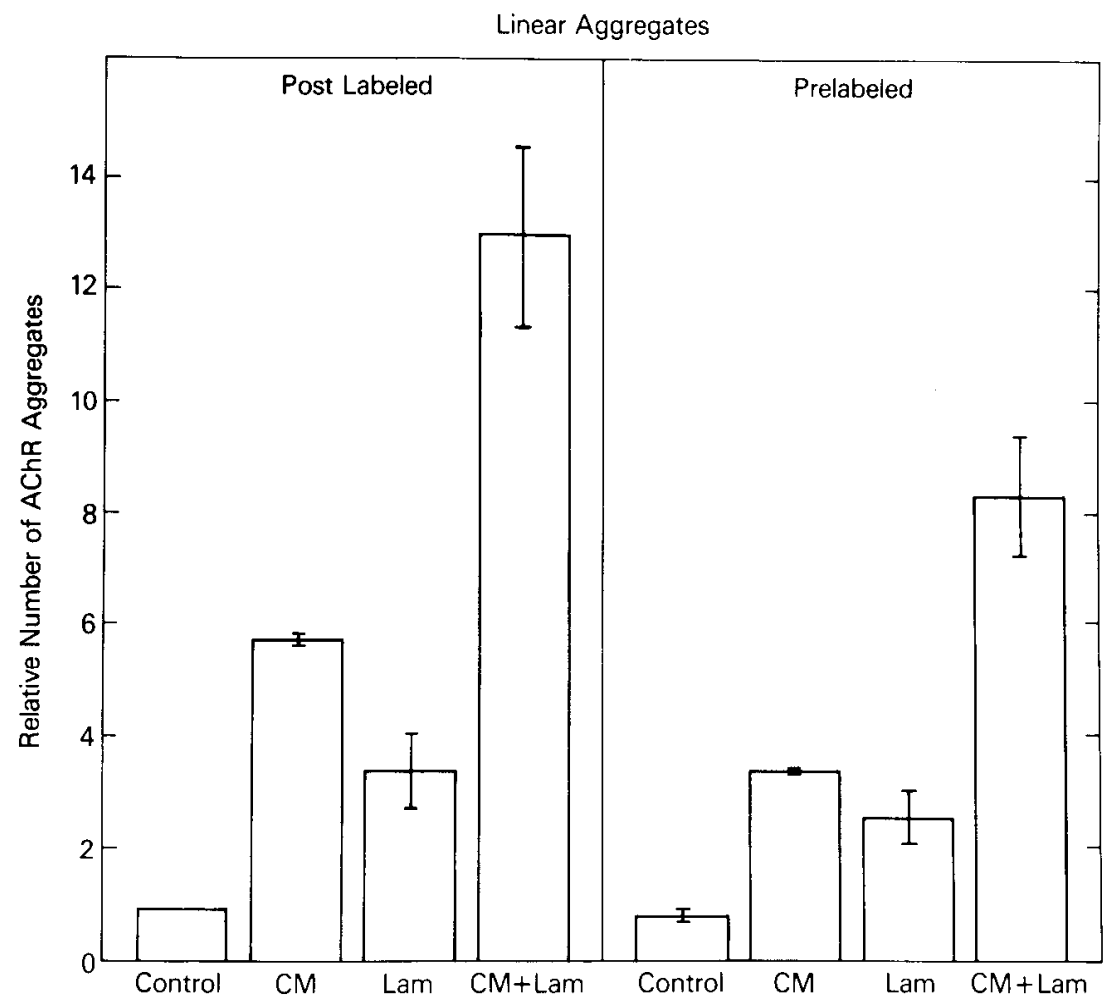

Figure 6. The effect of prelabeling of ACh receptors on the number of linear ACh receptor aggregates in 10-day-old rat muscle cell cultures incubated for 15 $\mathrm{hr}$ with the following materials, as indicated: control medium (Control), $4.2 \mu \mathrm{g}$ of laminin ( $L a m), 40 \mu \mathrm{g}$ of NCM $(C M)$, or laminin plus NCM. In $A$, the cultures were incubated with $100 \mathrm{nM}$ 'TMR- $\alpha \mathrm{BT}$ at the end of the 15 -hr incubation. In $B$, the cultures were incubated for $1 \mathrm{hr}$ with $100 \mathrm{nM}$ 'IMR- $\alpha \mathrm{B}^{\prime} \mathrm{T}$ ' and washed two times with control medium before the addition of control medium with or without laminin and NCM.

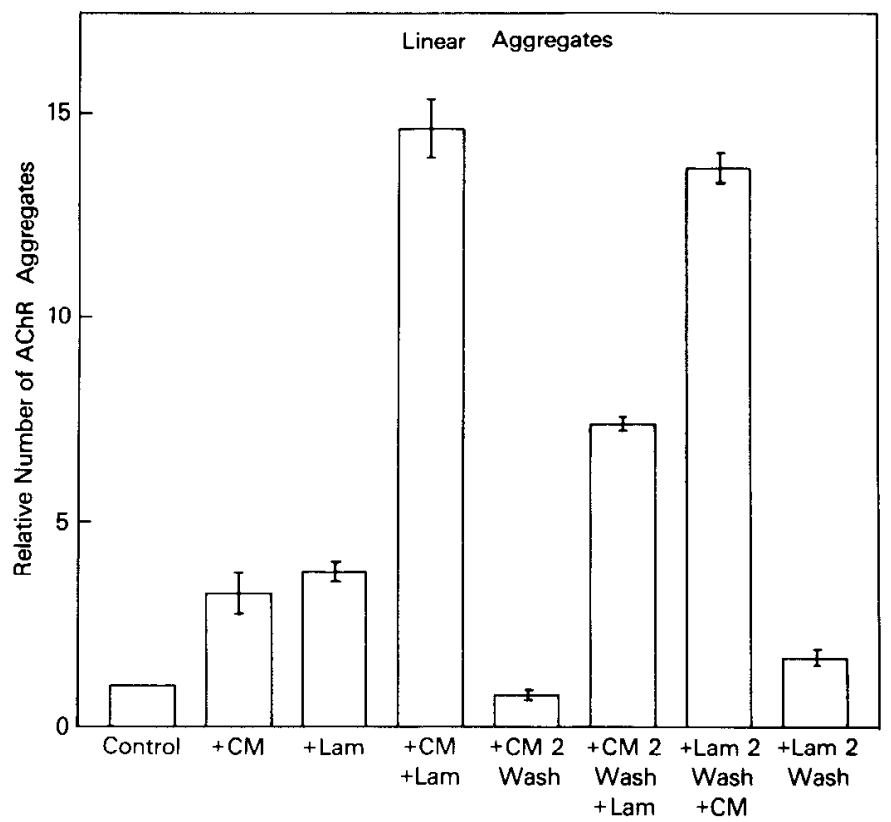

Figure 7. The effect of sequential addition of laminin and NCM on the number of linear ACh receptor $(A C h R)$ aggregates in rat muscle cell cultures. Myotubes in 8-day-old cultures were incubated with one or more of the following materials: control medium (Control), $36 \mu \mathrm{g}$ of NCM $(C M)$, or $4.2 \mu \mathrm{g}$ of laminin ( $L a m)$. The cultures were either incubated with the materials for $24 \mathrm{hr}$ (the four bars on the left) or were incubated for $2 \mathrm{hr}$ min, and the bound laminin is sufficient to enhance the receptor aggregation activity of subsequently added NCM. Thus, the interaction can take place at the myotube surface. It is possible that laminin binds the factor(s) in NCM, increasing their stability or their ability to interact with the myotube surface. Two lines of cvidence support this idea. First, whereas $2 \mathrm{hr}$ exposure to NCM followed by $22 \mathrm{hr}$ incubation gave little aggregation, addition of laminin during the second incubation period markedly enhanced aggregation. Second, preliminary evidence has suggested that the aggregating factor(s) in NCM binds to laminin (P. Sonderegger, H. C. Bauer, and M. Vigny, unpublished observation). The observation that bound laminin forms aggregates on the cell surface after several hours suggests another possible mechanism; that is, laminin itself may interact with the $\mathrm{ACh}$ receptor or other molecules at or near the cell surface and, in aggregating, may help to induce the aggregation of $\mathrm{ACh}$ receptors. We have, indeed, found that many of the laminin aggregates formed within $24 \mathrm{hr}$ after adding laminin or laminin plus NCM to the cultures are covering or overlapping $\mathrm{ACh}$ receptor-rich regions (unpublished results). Furthermore, we have found that

with the material indicated, washed once with control medium, and then incubated for $22 \mathrm{hr}$ with laminin, NCM, or control medium, as indicated. 

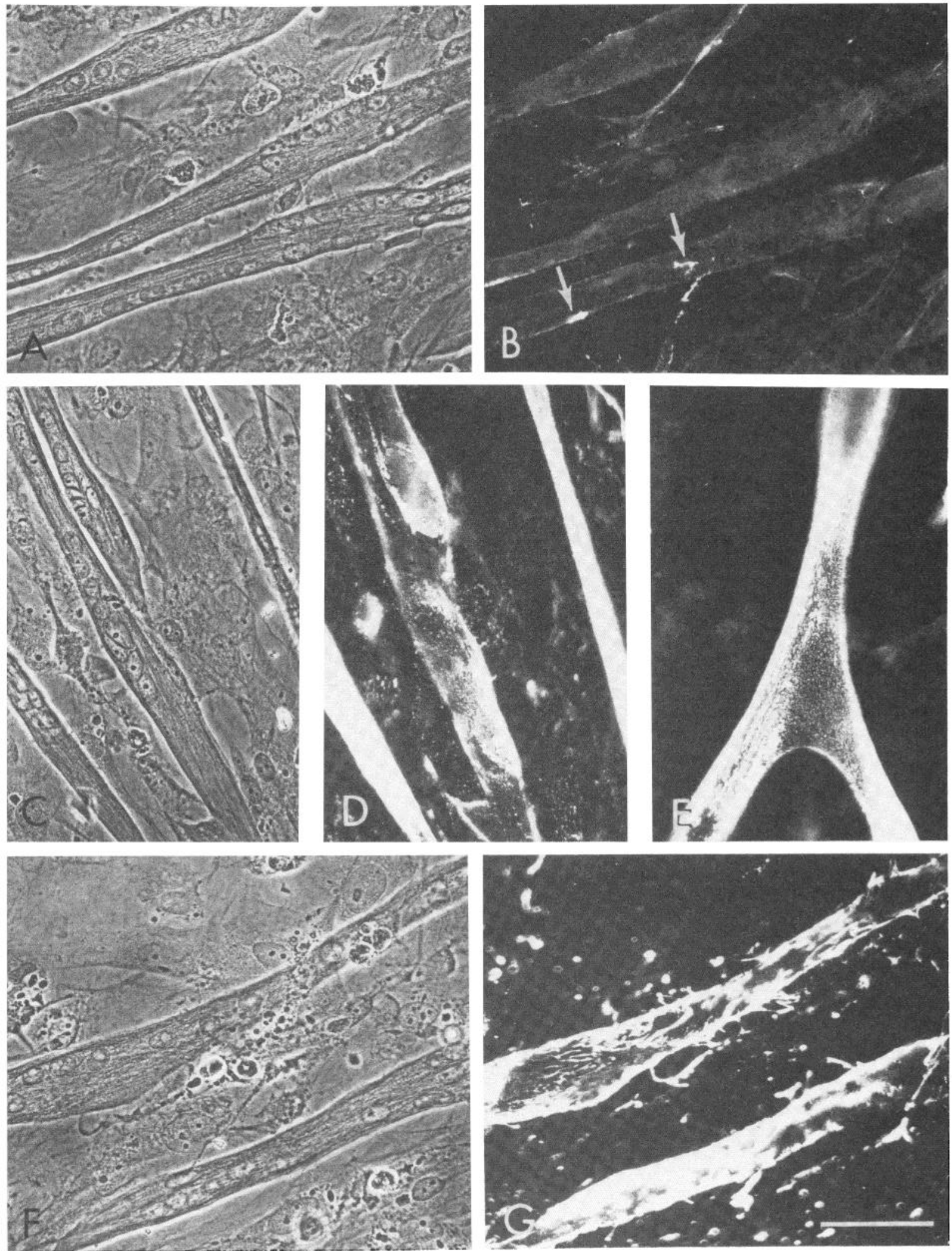

Figure 8. Phase contrast $(A, C$, and $F)$ and fluoresence $(B, D, E$, and $G$ ) photomicrographs of myotubes in 8-day-old rat muscle cell cultures, stained for laminin by indirect immunofluorescence. The cultures shown in $C$ to $G$ were incubated with $6 \mu$ g of laminin for $30 \mathrm{~min}(C, D$, and $E)$ or $24 \mathrm{hr}(F$ and $G)$ before washing, fixation, and immunostaining. The myotube surface has relatively low immunoreactivity for laminin, except for a few patches (arrows in $B$ ). At 30 min after addition of laminin, the immunoreactivity is relatively evenly distributed on the myotube surface $(D$ and $E)$. The distribution at this time is finely granular, but regions of myotubes which are out of focus appear continuously labeled and are artifactually bright. At 24 hr after addition of laminin, the immunoreactivity is relatively patchy $(G)$. The calibration bar is $50 \mu \mathrm{m}$. 
virtually all $\mathrm{ACh}$ receptor-rich regions on myotubes are coextensive with laminin-rich regions, both in untreated myotube cultures and in cultures treated with NCM or fetal brain extract to induce $\mathrm{ACh}$ receptor aggregation (Daniels et al., 1981; M. P. Daniels, M. Vigny, P. Sonderegger, H. -C. Bauer, and Z. Vogel, submitted for publication). On the other hand, laminin is not found exclusively in ACh receptor-rich regions, and both endogenous and added laminin can be found in regions of the myotube surface which do not have a high receptor density, suggesting that the presence of a high local concentration of laminin is not in itself sufficient to induce ACh receptor aggregation. Presumably, local differences in the myotube surface, surrounding matrix, or underlying structures would predispose certain areas to receptor aggregation.

Laminin is known to interact specifically with collagen type IV (Terranova et al., 1980), found only in basement membranes, and with heparan sulfate (Sakashita et al., 1980), a polysaccharide component of the basement membrane proteoglycan (Hassell et al., 1980). Thus, it is possible that the interaction of laminin with the myotube, neuronal factors, or ACh receptors is mediated through interactions with other basement membrane components; for example, one of the collagens (Kalcheim et al., 1982). As previously shown (Anderson and Fambrough, 1981; Bayne et al., 1981; Daniels et al., 1981; Silberstein et al., 1982), regions with high $\mathrm{ACh}$ receptor density on cultured myotubes are often enriched in immunoreactivity for HS proteoglycan and other basement membrane components in addition to laminin.

It is interesting to speculate on the possibility that laminin has a role in the organization of $\mathrm{ACh}$ receptors and basement membrane in the developing neuromuscular junction in vivo. Laminin immunoreactivity seems to be widespread on the surface of the developing muscle fiber, including the synaptic region, at very early stages of synaptic development (M. P. Daniels, Z. Vogel, and M. Vigny, unpublished results) and later (Daniels et al., 1981; Sanes, 1982). Thus, it is possible that, by binding or otherwise modulating the activity of factor(s) secreted locally by the nerve ending, laminin could enhance the local organization of components at the muscle cell surface.

\section{References}

Alitalo, K., M. Kurkineu, A. Vaheri, I. Virtanen, H. Rohde, and R. Timpl (1980) Basal lamina glycoproteins are produced by neuroblastoma cells. Nature 287: 465-466.

Anderson, M. J., and D. M. Fambrough (1981) Nerve-induced deposition of basal lamina during the development of an amphibian neuromuscular junction in cell culture. Soc. Neurosci. Abstr. 7: 670 .

Axelrod, D., P. Ravdin, D. E. Koppel, J. Schlessinger, W. W. Webh, and E. L. Elson (1976) Lateral motion of fluorescently labeled acetylcholine receptors in membranes of developing muscle fibers. Proc. Natl. Acad. Sci. U. S. A. 73: 4594-4598.

Bauer, H. C., M. P. Daniels, P. A. Pudimat, L. Jacques, H. Sugiyama, and C. N. Christian (1981) Characterization and partial purification of a neuronal factor which increases acetylcholine receptor aggregation on cultured muscle cells. Brain Res. 209: 395-404.

Bayne, E. K., J. Gardner, and D. M. Fambrough (1981) Monoclonal antibodies to extracellular matrix antigens in chicken skeletal muscle. In Monoclonal Antibodies to Neural Antigens, R. McKay, M. C. Raff, and L. F. Reichardt, eds., pp. 259-269, Cold Spring Harbor Laboratory, Cold Spring Harbor, NY.

Bloch, R. J., and B. Geiger (1980) The localization of acetylcholine receptor clusters in areas of cell-substrate contact in cultures of rat myotubes. Cell $21: 25-35$.

Bottenstein, J. E., and G. H. Sato (1979) Growth of a rat neuroblastoma cell line in serum-free supplemented medium. Proc. Natl. Acad. Sci. U. S. A. 76: 514-517.

Burden, S. J., P. B. Sargent, and U. J. McMahan (1979) Acetylcholine receptors in regenerating muscle accumulate at original synaptic sites in the absence of the nerve. J. Cell Biol. 82: 412-425.

Burrage, T. G., and T. L. Lentz (1981) Ultrastructural characterization of surface specializations containing high-density acetylcholine receptors on embryonic chick myotubes in vivo and in vitro. Dev. Biol. 85: 267-286.

Christian, C. N., P. G. Nelson, J. Peacock, and M. Nirenberg (1977) Synapse formation between two clonal cell lines. Science 196: 995-998.

Christian, C. N., M. P. Daniels, H. Sugiyama, 7. Vogel, I. Jacques, and P. G. Nelson (1978) A factor from neurons increases the number of acetylcholine receptor aggregates on cultured muscle cells. Proc. Natl. Acad. Sci. U. S. A. 75: 40114015.

Christian, C. N., H. C. Bauer, and S. Hasegawa (1981) Neuronal regulation of muscle cell acetylcholine receptor distribution, stability and concentration. Adv. Physiol. Sci. 36: 275-283.

Chung, E., R. K. Rhodes, and E. J. Miller (1976) Isolation of three collagenous components of probable basement membrane origin from several tissues. Biochem. Biophys. Res. Commun. 71: 1167-1174.

Daniels, M. P., M. Vigny, H. Bauer, P. Sonderegger, and Z. Vogel (1981) Laminin and other basement membrane proteins codistribute with acetylcholine receptors on the surface of cultured myotubes. Soc. Neurosci. Abstr. 7: 143.

Dulbecco, R., and M. Vogt (1954) Plaque formation and isolation of pure lines with poliomyelitis viruses. J. Exp. Med. 99: 167-182.

Fischbach, G. D., and S. A. Cohen (1973) The distribution of acetylcholine sensitivity over uninnervated and innervated muscle fibers grown in cell culture. Dev. Biol. 31: 147-162.

Foidart, J. M., J. J. Berman, L. Paglia, S. Rennard, S. Abe, A. Perantoni, and G. R. Martin (1980) Syntheses of fibronectin, laminin, and several collagens by a liver-derived epithelial line. Lab. Invest. 42: 525-532.

Hasegawa, S., H. C. Bauer, and C. N. Christian (1980) Effects of neuronal cell factors on kinetics and aggregation of cultured rat muscle acetylcholine receptors. Soc. Neurosci. Abstr. 6: 375 .

Hassell, J. R., P. G. Robey, H. -J. Barrach, J. Wilczek, S. I. Rennard, and G. R. Martin (1980) Isolation of a heparan sulfate-containing proteoglycan from basement membrane. Proc. Natl. Acad. Sci. U. S. A. 77: 4494-4498.

Jacob, M., and T. L. Lentz (1979) Localization of acetylcholine receptors by means of horseradish peroxidase- $\alpha$-bungarotoxin during formation and development of the neuromuscular junction in the chick embryo. J. Cell Biol. 82: 195-211.

Jessell, T. M., R. E. Siegel, and G. D. Fischbach (1979) Induction of acetylcholine receptors on cultured skeletal muscle by a factor extracted from brain and spinal cord. Proc. Natl. Acad. Sci. U. S. A. 76: 5397-5401.

Kalcheim, C., Z. Vogel, and D. Duksin (1982) Embryonic brain extract induces collagen biosynthesis in cultured muscle cells: Involvement in acetylcholine receptor aggregation. Proc. Natl. Acad. Sci. U. S. A. 79: 3077-3081.

Kelly, A. M., and S. I. Zacks (1969) The fine structure of motor endplate morphogenesis. J. Cell Biol. 12: 154-169. 
Lowry, O. H., N. J. Rosebrough, A. L. Farr, and R. G. Randall (1951) Protein measurement with the Folin phenol reagent. J. Biol. Chem. 193: 265-275.

Orkin, R. W., P. Gehron, E. B. McGoodwin, G. R. Martin, T. Valentine, and R. Swarm (1977) A murine tumor producing a matrix of basement membrane. J. Exp. Med. 145: 204-220.

Peacock, J. H., D. Rush, and M. Noble (1977) Mouse myogenic cell lines G7 and G8. Soc. Neurosci. Abstr. 3: 526.

Podleski, T. R., D. Axelrod, P. Ravdin, I. Greenberg, M. M. Johnson, and M. M. Salpeter (1978) Nerve extract induces increase and redistribution of acetylcholine receptors on cloned muscle cells. Proc. Natl. Acad. Sci. U. S. A. 75: 20352039.

Rennard, S. I., R. Berg, G. R. Martin, J. M. Foidart, and P. G. Robey (1980) Enzyme-linked immunoassay (ELISA) for connective tissue components. Anal. Biochem. 104: 205-214.

Rubin, L. L., A. S. Gordon, and U. J. McMahan (1980) Basal lamina fraction from the electric organ of Torpedo organizes acetylcholine receptors on cultured myotubes. Soc. Neurosci. Abstr. 6: 330.

Sakashita, S., E. Engvall, and E. Ruoslahti (1980) Basement membrane glycoprotein laminin binds to heparin. FEBS Lett. 116: 243-246.

Salpeter, M. M., S. Spanton, K. Holley, and T. Podleski (1982) Brain extract causes acetylcholine receptor redistribution which mimics some early events at developing neuromuscular junctions. J. Cell Biol. 93: 417-425.

Sanes, J. R. (1982) Laminin, fibronectin, and collagen in synaptic and extrasynaptic portions of muscle fiber basement membrane. J. Cell Biol. 93: 442-451.

Sanes, J. R., and Z. W. Hall (1979) Antibodies that bind specifically to synaptic sites on muscle fiber basal lamina. J. Cell Biol. 83: 357-370.

Sanes, J. R., L. M. Marshall, and U. J. McMahan (1978)
Reinnervation of muscle fiber basal lamina after removal of myofibers. Differentiation of regenerating axons at original synaptic sites. J. Cell Biol. 78: 176-198.

Schaffner, A. E., and M. P. Daniels (1982) Conditioned medium from cultures of embryonic neurons contains a high molecular weight factor which induces acetylcholine receptor aggregation on cultured myotubes. J. Neurosci. 2: 623-632.

Silberstein, L., N. C. Inestrosa, and Z. W. Hall (1982) Aneural muscle cell cultures make synaptic basal lamina components. Nature 295: 143-145.

Sugiyama, H. (1979) Multiple forms of acetylcholinesterase in clonal muscle cells. FEBS Lett. 84: 257-260.

Sytkowski, A., and Z. Vogel (1973) Characteristics of acetylcholine receptors on skeletal muscle grown in vitro. Trans. Am. Soc. Neurochem. 5: 130.

Sytkowski, A. J., Z. Vogel, and M. W. Nirenberg (1973) Development of acetylcholine receptor clusters on cultured muscle cells. Proc. Natl. Acad. Sci. U. S. A. 70: 270-274.

Terranova, V. P., D. H. Rohrbach, and G. R. Martin (1980) Kole of laminin in the attachment of PAM 212 (epithelial) cells to basement membrane collagen. Cell 22: 719-726.

Timpl, R., H. Rohde, P. G. Robey, S. I. Rennard, J. -M. Foidart, and G. R. Martin (1979) Laminin-A glycoprotein from basement membranes. J. Biol. Chem. 254: 9933-9937.

Vogel, Z., A. J. Sytkowski, and M. W. Nirenberg (1972) Acetylcholine receptors of muscle grown in vitro. Proc. Natl. Acad. Sci. U. S. A. 69: 3180-3184.

Yamada, K. M., S. S. Yamada, and I. Pastan (1976) Cell surface protein partially restores morphology, adhesiveness, and contact inhibition of movement to transformed fibroblasts. Proc. Natl. Acad. Sci. U. S. A. 73: 1217-1221.

Yaoita, H., J. -M. Foidart, and S. I. Katz (1978) Localization of the collagenous component in skin basement membrane. J. Invest. Dermatol. 70: 191-193. 